\title{
Mitral stenosis in the Maroteaux-Lamy syndrome: a treatable cause of dyspnoea
}

\author{
Thomas H. Marwick, Bruce Bastian, Clifford F. Hughes and Brian P. Bailey
}

\begin{abstract}
Hallstrom Institute of Cardiology and Cardiothoracic Surgical Unit, Royal Prince Alfred Hospital, Missenden Road, Camperdown, Sydney, NSW 2050, Australia
\end{abstract}

\begin{abstract}
Summary: The case is reported of a young woman with the Maroteaux-Lamy syndrome (mucopolysaccharidosis type VI) who presented with rapidly progressive dyspnoea due to mitral stenosis. Mitral valve replacement was performed and the appearance of the valve was typical of mucopolysaccharide infiltration. Dyspnoea in patients with the Maroteaux - Lamy syndrome may be due primarily to cardiac valve involvement, and in this setting, valve surgery is safe and effective.
\end{abstract}

\section{Introduction}

The mucopolysaccharidoses are characterized by infiltration of skeletal structures, cornea, meninges, blood vessels and myocardium, among other structures. ${ }^{1}$ Cardiac involvement has been reported in $85 \%$ of patients with Hurler's syndrome, ${ }^{2}$ and most commonly presents as mitral regurgitation. The incidence of valvular disease in other mucopolysaccharidoses in variable, and was first described in type VI (Maroteaux-Lamy syndrome) in $1972 .^{3}$

Dyspnoea is a common symptom in patients with mucopolysaccharidoses, and may presage a terminal course from restrictive lung disease, secondary to chest wall deformity. Valvular disease may be difficult to recognize clinically in such subjects, ${ }^{4}$ but is important as a potentially treatable cause of dyspnoea. We report a young subject with the Maroteaux-Lamy syndrome who presented with rapidly progressive mitral stenosis, and who responded well to mitral valve surgery.

\section{Case report}

A 25 year old single woman was admitted to the hospital with progressive exertional dyspnoea. A diagnosis of the Maroteaux - Lamy syndrome had been made in childhood, but apart from a presentation with spinal cord compression, requiring cer-

Correspondence: T. Marwick, M.B., B.S., F.R.A.C.P. Service du Pathologie Cardiovasculaire, Cliniques Universitaires St Luc, Avenue Hippocrate 10, Bte 28.81, 1200 Brussels, Belgium.

Accepted: 15 June 1991 vical laminectomy, she had remained well. There was no other significant history, in particular, no history of rheumatic fever. About 5 years prior to this presentation, she had developed progressive exertional dyspnoea. One year before admission, she became unable to perform housework, and developed orthopnoea and paroxysmal nocturnal dyspnoea. The presence of mitral valve disease was recognized, but although her symptoms transiently improved with frusemide therapy, they rapidly became limiting again.

Inspection revealed a young woman of short stature and dysmorphic features, dyspnoeic at rest. Cardiovascular examination indicated the presence of mitral valve disease, with dominant mitral stenosis and mild mitral regurgitation, and clinical signs of pulmonary hypertension. The diagnosis was supported by electrocardiographic and radiological findings. Two dimensional and M-mode echocardiography confirmed the presence of a stenosed and rigid valve, with commisural fusion, resembling a rheumatic valve (Figure 1). The aortic valve was tricuspid and mildly echodense, with normal leaflet excursion. Cardiac catheterization demonstrated a mean mitral valve gradient of $18 \mathrm{mmHg}$, with a valve orifice of $0.83 \mathrm{~cm}$. The pulmonary artery pressure was $33 / 23 \mathrm{mmHg}$. Left ventricular contraction was normal on ventriculography, and there was no mitral regurgitation. There was no systolic aortic valve gradient, and minimal aortic regurgitation.

At surgery, the mitral valve was thickened, nodular, and calcified. The myocardium was described as being rubbery in texture, suggesting mucopolysaccharide infiltration. Histological examination of the excised valve showed infiltration with foamy cells and fibrosis, consistent with the 


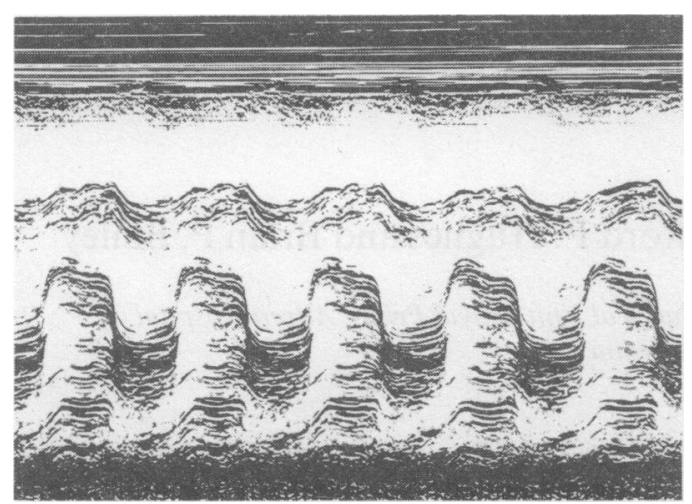

Figure 1 M-mode echocardiograph of the mitral valve, showing thickening and stenosis.

Maroteaux-Lamy syndrome. The mitral valve was replaced with a size $2 \mathrm{M}$ Starr-Edwards 6120 prosthesis.

Initial follow-up demonstrated marked improvement of exercise tolerance, and regression of signs of pulmonary hypertension. Three years following surgery, the patient again complained of exertional dyspnoea, and investigation revealed mild to moderate aortic stenosis (Doppler peak gradient $45 \mathrm{mmHg}$ ), with normal prosthetic valve and left ventricular function. Despite recent symptoms, her clinical state remains improved, in comparison with her status before valve replacement.

\section{Discussion}

The Maroteaux-Lamy syndrome is characterized by clinical features similar to the other mucopoly-

\section{References}

1. McKusick, V.A. The mucopolysaccharidoses. In: McKusick, V.A. (ed.) Hereditable Disorders of Connective Tissues, 4th ed. C.V. Mosby, St Louis, 1972, p. 541.

2. Emanuel, R.W. Gargoylism with cardiovascular involvement in two brothers. Br Heart $J$ 1954, 16: 417-418.

3. Krovetz, L.J. \& Schliebler, G.L. Cardiovascular manifestations of genetic mucopolysaccharidoses. Birth Defects 1972, 8: $192-195$.

4. Ireland, M.A. \& Rowlands, D.B. Mucopolysaccharidosis type IV as a cause of mitral stenosis in an adult. Br Heart $J$ 1981, 46: 113-115.

5. McKusick, V.A. The mucopolysaccharidoses. In: McKusick, V.A. (ed.) Hereditable Disorders of Connective Tissue, 4th ed. C.V. Mosby, St Louis, 1972, pp. 618.

6. Henderson, J.L., MacGregor, A.R., Thannhauser, S.J. \& Holden, R. The pathology and biochemistry of gargoylism: a report of three cases with a review of the literature. Arch Dis Child 1952, 27: 230-253. saccharidoses, but is distinguished by the preservation of mental function, and by the predominant urinary excretion of dermatan sulphate. ${ }^{5}$ Heart valve involvement has similarities with that of rheumatic fever, with nodular thickening along the free margin and shortening and thickening of the chordae. ${ }^{6}$ However, the valve disease may be rapidly progressive, and the tissue infiltration is with mucopolysaccharide, rather than inflammatory tissue alone. Mitral stenosis was first described in the mucopolysaccharidoses in $1960,{ }^{7}$ but has been reported only once before in combination with the Maroteaux-Lamy syndrome. ${ }^{8}$

Reluctance to perform cardiac surgery in patients with the mucopolysaccharidoses may arise because of poor life expectancy, due to respiratory complications, mental retardation, or concern that infiltrated myocardial tissue would be unable to withstand repair. ${ }^{9}$ Our patient had normal mental function, and was otherwise well. The absence of operative or subsequent technical problems is consonant with the limited experience of other groups performing cardiac surgery in similar patients.., 10

Progressive dyspnoea in patients with mucopolysaccharidoses is often attributed to terminal respiratory disease. The possibility of significant valvular heart disease is easily overlooked in the evaluation of these patients, and surgical treatment should not be disregarded in this setting. Despite the progressive nature of this disease, this case? suggests that valvular surgery may provide worthwhile palliation of symptoms for several years.

7. Vanace, P.W., Friedman, S. \& Wagner, B.M. Mitral stenosis in an atypical case of gargoylism. Circulation 1960, 21: $80-88$.

8. Schieken, R.M., Kerber, R.E., Ionasescu, V.V. \& Zellweger, H. Cardiac manifestations of the mucopolysaccharidoses. Circulation 1975, 52: 700-705.

9. Glober, G.A., Tanaka, K.R., Turner, J.A. \& Liu, C.K. Mucopolysaccharidosis, an unusual cause of cardiac valvular disease. Am J Cardiol 1968, 22: 133-136.

10. Herd, J.K., Subramanian, S. \& Robinson, H. Type III mucopolysaccharidosis: a report of a case with severe mitral valve involvement. J Pediatr 1973, 82: 101-104. 